\title{
Development of the simultaneous analysis of choline salicylate, lidocaine hydrochloride and preservatives in a new dental gel by HPLC method
}

\author{
Yuliia Masliii ${ }^{*}$, \\ Ivan Bezruk ${ }^{2}$, \\ Anna Materiienko ${ }^{3}$, \\ Olena Ruban ${ }^{1}$, \\ Liudas Ivanauskas ${ }^{4}$, \\ Mariia Velia ${ }^{1}$ \\ ${ }^{1}$ Department of Industrial Technology of Drugs, \\ National University of Pharmacy, \\ 53 Pushkinska Street, \\ 61002 Kharkiv, Ukraine \\ ${ }^{2}$ Department of Pharmaceutical Chemistry, \\ National University of Pharmacy, \\ 53 Pushkinska Street, \\ 61002 Kharkiv, Ukraine \\ ${ }^{3}$ Department of the Quality, \\ Standartization and Certification of Medicines, \\ National University of Pharmacy, \\ 53 Pushkinska Street, \\ 61002 Kharkiv, Ukraine \\ ${ }^{4}$ Department of Analytical \\ and Toxicological Chemistry, \\ Lithuanian University of Health Sciences, \\ 13 Sukileliai Avenue, \\ 50161 Kaunas, Lithuania
}

\begin{abstract}
A new high-performance liquid chromatography (HPLC) method for the simultaneous quantitative determination of active pharmaceutical substances and preservatives in a new dental medication has been developed. The optimization of HPLC method parameters was done through studies of a mobile phase composition and a detection wavelength. Our developing method uses an ACE C18 column $(250 \times 4.6 \mathrm{~mm}, 5 \mu \mathrm{m})$ and a gradient mode for separation with the acetonitrile and phosphate buffer solution (adjusted to $\mathrm{pH} 3.0$ ) as mobile phases. The flow rate is $1 \mathrm{ml} /$ $\mathrm{min}$, and the detection was set at $260 \mathrm{~nm}$ (DAD). The method was evaluated according to the ICH guidelines and the State Pharmacopoeia of Ukraine in terms of specificity, accuracy, linearity and precision (repeatability and intermediate precision). The limit of detection and the limit of quantification were also calculated. The developed method was put in place for the analysis of a combined dental gel to a quantitative determination of the APIs (choline salicylate, lidocaine hydrochloride) and preservatives (methylparaben, propylparaben).
\end{abstract}

Keywords: choline salicylate, dental gel, HPLC, lidocaine hydrochloride, preservatives

\section{INTRODUCTION}

The combined dental gel is a new pharmaceutical preparation, which has been developed for the treatment of inflammatory periodontal dis-

\footnotetext{
* Corresponding author. Email: julia.masliy@gmail.com
}

eases and oral mucosa, as well as to adapt to dentures. The choice of active pharmaceutical ingredients in the developed dental gel was determined based on the functional state of the oral mucosa and the pathogenesis of inflammatory diseases of periodontal tissues and is associated with the use of antimicrobial, anti-inflammatory, hemostatic 
and regenerating actions, which are the herbal tincture Phitodent, choline salicylate (ChSal), and analgesic effect, provided by lidocaine hydrochloride (LidHyd). The combination of synthetic and natural components of the gel allows potentiating their pharmacological activity [1]. For keeping the microbiological quality of the developed dosage form it also contains two preservatives - methylparaben (MP) and propylparaben (PP) [2, 3].

ChSal has a desirable analgesic-antipyretic activity and has noteworthy pharmacologic and therapeutic properties useful in different treatments. It has a good absorbability when applied to mucous membranes, which allows using it in dentistry. The literature describes a successful use of ChSal in many products for the therapy of different dental illness [4-12.

Lidocaine is an amide-type local anesthetic, which is commonly used in injectable dosage forms or designed for local applying to mucous membranes. LidHyd is characterized by a fast-evolving and an intermediate duration of action. Anesthesia is achieved within a few minutes, depending on the medication administration site. Due to these properties, it is widely used in the therapy of a wide range of oral cavity problems and during dental procedures [13-18].

Some methods for determination of ChSal are presented in literature data, such as HPLC [19] in over-the-counter (OTC) drugs, a spectro-fluorometric method of Rowland, and Riegelman [8] in rat plasma.

The European Pharmacopoeia recommended the potentiometric titration method with hydrochloric acid as a titrant for the assay of LidHyd [20]. More different methods of LidHyd analysis are presented: it can be analysed by various HPLC methods [21-23], by a partial least-squares calibration (PLS) method [24] and by a programmed temperature GLC assay [25].

Literature describes a lot of analytical procedures for the determination of various preservatives, either individually or in a mixture with other substances using different analytical methods [26-33].

None of the above-listed papers describe a successfully validated method that was applied for the simultaneous analysis of the mentioned components during one analysis.

The leading focus of our work has been to develop and validate a rapid HPLC method for the ac- tive pharmaceutical substances quantification such as choline salicylate and lidocaine hydrochloride and preservatives - methylparaben and propylparaben - at the same conditions in the pharmaceutical preparation.

The developed method can be applied for a regular analytic control throughout the dental gel manufacturing: quantity determination of ChSal, LidHyd and preservatives in gel is performed in accordance with the validation parameters for the medications. Also the developed method can be used for in vitro studies from topical formulations, through different types of diffusion membranes [34].

\section{EXPERIMENTAL}

\section{Materials and reagents}

Acetonitrile (HPLC grade) was purchased from Sigma-Aldrich GmbH (Switzerland). The Millipore (USA) water purification system was used to obtain HPLC grade water.

ChSal was purchased from Basf Pharma, Siegfried (Switzerland). LidHyd was purchased from Societa Italiana Medicinali Scandicci (Italy). MP was purchased from Wuhu Huahai Biology Engineering Co., LTD (China) and PP was purchased from Ueno Fine Chemicals Industry (Japan). All reference standards were purchased from the State Pharmacopoeia of Ukraine (SPhU) (Ukraine).

The analysed dental gel contained $8 \%$ of ChSal, $1.5 \%$ of LidHyd, $0.2 \%$ of preservatives $(0.15 \%$ of MP and $0.05 \%$ of PP). Also, the gel contained $15 \%$ of herbal tincture Phitodent (purchased from PJSC Chemical \& Pharmaceutical Plant Chervona Zirka, Kharkiv, Ukraine) [35]. The other excipients of the gel formulation carbomer Polacril 40P, OraRez ${ }^{\circ} \mathrm{W}-100 \mathrm{~L} 16,10 \%$ solution of sodium hydroxide and purified water [1]. For the validation study a placebo was prepared with the usage of excipients and tincture.

All solutions were prepared according to the procedures described below.

Test solution. $1.0 \mathrm{~g}$ of the accurately weighted gel was placed into a $100.0 \mathrm{ml}$ volumetric flask, $60 \mathrm{ml}$ of methanol were added, ultrasonicated for 5 minutes, made up to the mark with methanol and mixed.

The reference solution was prepared in a concentration of ChSal $0.8 \mathrm{mg} / \mathrm{ml}$, LidHyd $0.15 \mathrm{mg} /$ $\mathrm{ml}, \mathrm{MP} 0.015 \mathrm{mg} / \mathrm{ml}$ and PP $0.01 \mathrm{mg} / \mathrm{ml}$.

The placebo solution was prepared by the same procedure, as the test solution, using the placebo gel. 


\section{HPLC procedure}

A Shimadzu Nexera X2 LC-30AD HPLC system (Shimadzu, Japan) composed of a quaternary pump, an on-line degasser, a column temperature controller, a SIL-30AC autosampler (Shimadzu, Japan); a CTO-20AC thermostat (Shimadzu, Japan) as well as a SPD-M20A diode array detector (DAD) were used for analysis.

An ultrasonic Cleaner Set (Wise Clean WUCA06H, Witeg Labortechnik GmbH, Germany) was used for ultrasonication, and an analytical balance Libra UniBloc AUW120D (Shimadzu Analytical Scale, Japan) was used for weighing.

The liquid chromatography separation of active substances and preservatives was carried out on an ACE C18 column $250 \mathrm{~mm} \times 4.6 \mathrm{~mm}, 5 \mu \mathrm{m}$ particle size. The mobile phase was of a mixture of acetonitrile (mobile phase B) with a $3.0 \mathrm{~g} / \mathrm{L}$ sodium phosphate dibasic solution adjusted to $\mathrm{pH} 3.0$ (mobile phase A). The separation was carried out by a gradient elution mode using the gradient program presented below:

$0-3$ min: $25 \%$ B; $3-13$ min: $25 \rightarrow 50 \%$ B; $13-20$ min: $50 \%$ B; $20-21$ min: $50 \rightarrow 25 \%$ B; $21-25$ min: $25 \%$ B.

A $0.45 \mu \mathrm{m}$ membrane filter was used for mobile phases before usage. The flow rate was $1 \mathrm{ml} / \mathrm{min}$ and the injection volume was $10 \mu \mathrm{L}$. The eluent was controlled with a DAD detector set at $260 \mathrm{~nm}$. During the analysis, the column temperature was $30^{\circ} \mathrm{C}$.

\section{Validation study}

The developed method was validated according to the International Conference on Harmonization (ICH) Q2 (R1) requirements [36] and SPhU requirements 5.3.N.2 [37]. The specificity, linearity, the limit of detection (LOD), the limit of quantification (LOQ), accuracy, precision, and stability validation parameters were studied.

\section{RESULTS AND DISCUSSION}

According to the above-mentioned literature sources, a column C18 was mostly used for the analysis of studying compounds [19,21-23], thus this type of a sorbent was chosen in the present investigation.

The development and optimization of HPLC method parameters was done through the studies of a mobile phase composition, a gradient program and a detection wavelength. To detect $\mathrm{ChSal}$, LidHyd and preservatives during one analysis, the spectra of all mentioned components were collected with DAD and $260 \mathrm{~nm}$ was selected as the most appropriate. In this paper, acetonitrile as mobile phase $B$ and phosphate buffer as mobile phase A were used. To achieve suitable peak shapes as well as separation, different $\mathrm{pH}$ of buffers was compared, due to the chemical properties of analysed components. The obtained results indicated that $3.0 \mathrm{pH}$ provided both satisfactory resolution and acceptable peak shapes. Also, various gradient modes were applied to obtain the optimal time of analysis separation between components and gel matrix. The most suitable is presented in the method description.

\section{System suitability}

The chromatographic separation of ChSal, LidHyd substances, and MP, PP preservatives, as explained above, was performed on a C18 column (ACE C18, $250 \mathrm{~mm} \times 4.6 \mathrm{~mm}, 5 \mu \mathrm{m}$ particle size) in the gradient mode using a mix of acetonitrile with a phosphate buffer solution $\mathrm{pH} 3.0 \pm 0.5$ as a mobile phase. The usage of gradient allows quantifying all ingredients in the same chromatographic conditions.

The chromatographic system must satisfy the pharmacopoeia for suitability test requirements [20, 37, 38]. The results of system suitability in comparison with the required limits are shown in Table 1 .

Table 1. System suitability test for the developed HPLC method

\begin{tabular}{|c|c|c|c|c|c|}
\hline \multirow{2}{*}{ Parameter } & \multirow{2}{*}{ Required limits } & \multicolumn{4}{|c|}{ Results } \\
\hline & & LidHyd & ChSal & MP & PP \\
\hline Retention time, min & - & 5.174 & 8.470 & 10.122 & 15.990 \\
\hline RSD, \% & $\leq 1(n \geq 5)$ & 0.31 & 0.17 & 0.16 & 0.15 \\
\hline Resolution (Rs) & $>1.5$ & - & 13.637 & 6.990 & 25.566 \\
\hline Capacity factor $\left(\mathrm{K}^{\prime}\right)$ & $>1$ & 1.070 & 2.388 & 3.049 & 5.396 \\
\hline Tailing factor $(\mathrm{T})$ & $0.8<T<1.5$ & 1.302 & 0.952 & 1.185 & 1.162 \\
\hline Theoretical plate number (N) & $>3000$ & 7334 & 19637 & 30758 & 78600 \\
\hline
\end{tabular}




\section{Validation study}

\section{Specificity}

The retention times of the peaks of investigated substances coincided in the chromatograms of the test solution and corresponded to the retention times of the peaks of all substances in the chromatogram of the reference solution.

On the blank chromatogram there are no peaks, the retention time of which would coincide with the retention time of the peaks of analysed substances. The chromatogram of the placebo solution shows that there were no interfering reactions between the auxiliary and active substances or preservatives in the developed dental gel, which shows the specificity of the developed method.

A chromatogram comparison of the test solution, reference solution and the placebo solution with all analysed compounds (active substances and preservatives) is shown in the Figure.

\section{Linearity, $L O D, L O Q$}

A linear relationship was achieved between the component's peak area and concentrations [39]. Calibra- tion curves were linear over a concentration range of $120-180 \mu \mathrm{g} / \mathrm{ml}$ for LidHyd, $640-960 \mu \mathrm{g} / \mathrm{ml}$ for ChSal, $12-18 \mu \mathrm{g} / \mathrm{ml}$ for MP and $4-6 \mu \mathrm{g} / \mathrm{ml}$ for PP.

The LOD was expressed as a concentration that gives a signal to noise ratio of $2: 1$ or 3:1, and the LOQ was measured in terms of a signal to noise ratio of 10:1 [36, 37].

The results of linearity, given in Table 2, show a good correlation between the peak area of analysed compounds and the concentration with $r>0.9998$. Also, LOD and LOQ were calculated for each component and presented in Table 2.

\section{Accuracy}

The recovery was $100 \pm 2 \%$ for all samples with $\%$ RSD less than $1 \%$ (Table 3 ). Thereby, the proposed analytical method for the determination of the active substances and preservatives was quite accurate.

\section{Precision}

The RSD\% were found to be less than $1 \%$ for the intra-day and inter-day precision for every analysed component. The results are summarised in Table 4.

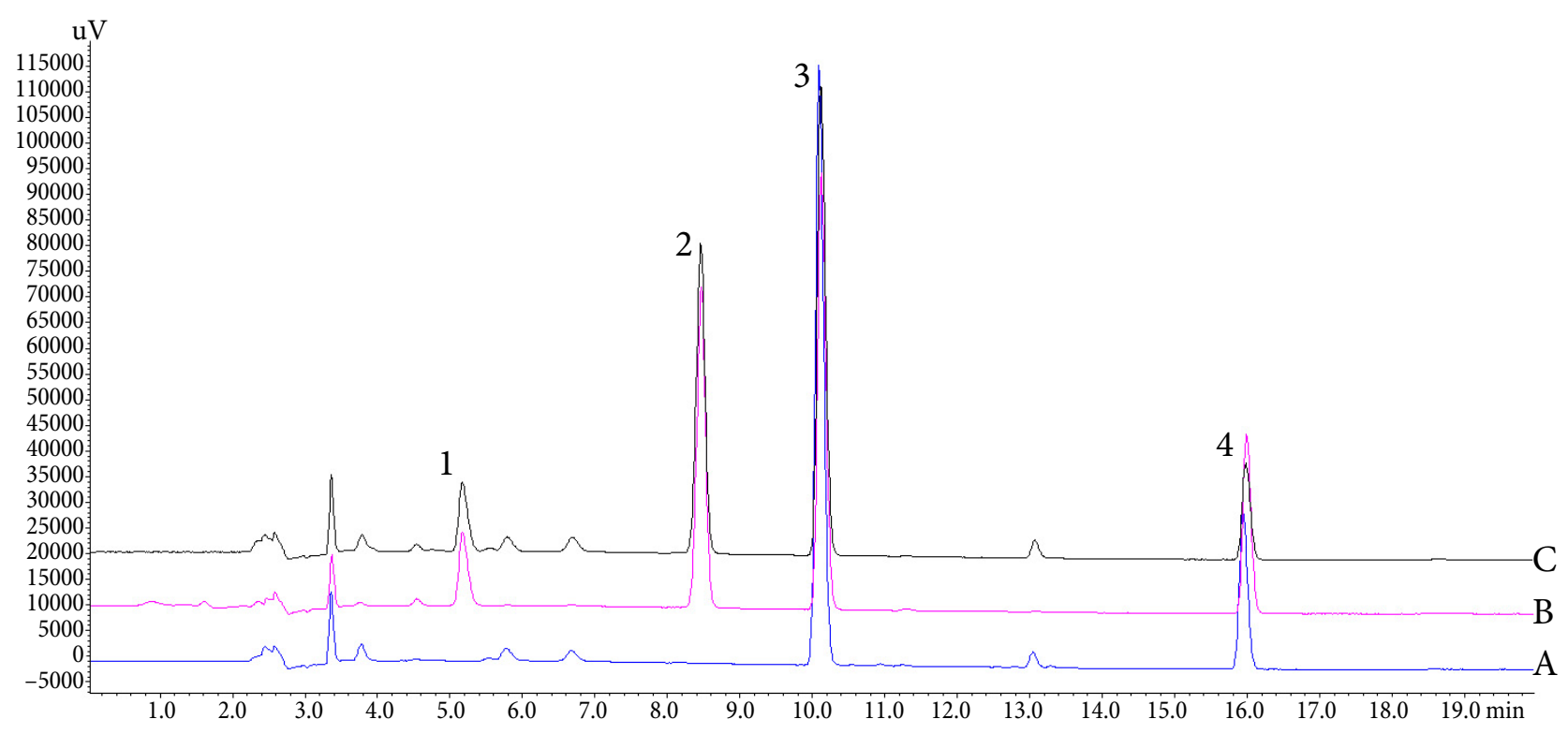

Figure. The chromatograms of test solution (C), reference solution (B) and placebo solution (A): 1 is lidocaine hydrochloride, 2 is choline salicylate, 3 is methylparaben, 4 is propylparaben. Coloured online

Table 2. Linearity, LOD and LOQ parameters of the developed HPLC assay method

\begin{tabular}{c|c|c|c|c|c|c}
\hline Component & Concentration, $\boldsymbol{\mu g} / \mathbf{m l}$ & Equation & $\mathbf{r}^{2}$ & $\mathbf{S}_{\mathbf{0}}$ & $\mathbf{L O D}, \boldsymbol{\mu g} / \mathbf{m l}$ & $\mathbf{L O Q}, \boldsymbol{\mu g} / \mathbf{m l}$ \\
\hline LidHyd & $120-180$ & $y=1.01 x-0.8012$ & 0.9999 & 0.30 & 2.23 & 6.75 \\
\hline ChSal & $640-960$ & $y=0.9836 x+1.8336$ & 0.9997 & 0.49 & 16.98 & 51.46 \\
\hline MP & $12-18$ & $y=0.9951 x+0.5783$ & 0.9999 & 0.21 & 0.20 & 0.60 \\
\hline PP & $4-6$ & $y=0.9899 x+1.1669$ & 0.9998 & 0.21 & 0.09 & 0.29 \\
\hline
\end{tabular}


Table 3. Accuracy parameters of the developed HPLC assay method

\begin{tabular}{ccc}
\hline Component & Concentration obtained, \% & RSD (\%) Equation \\
\hline LidHyd & $100.18 \pm 0.33$ & 0.21 \\
\hline ChSal & $100.23 \pm 0.65$ & 0.36 \\
\hline MP & $100.10 \pm 0.27$ & 0.16 \\
\hline PP & $100.17 \pm 0.50$ & 0.28 \\
\hline
\end{tabular}

Table 4. Precision study results of the developed HPLC method

\begin{tabular}{c|c|c|c}
\hline \multirow{2}{*}{ Component } & \multicolumn{3}{|c}{ RSD, \% (n= 5) } \\
\cline { 2 - 4 } & $\mathbf{8 0}$ & $\mathbf{1 0 0}$ & $\mathbf{1 2 0}$ \\
\hline \multicolumn{4}{|c}{ Intra-day precision } \\
\hline LidHyd & 0.61 & 0.30 & 0.41 \\
\hline ChSal & 0.39 & 0.27 & 0.23 \\
\hline MP & 0.54 & 0.32 & 0.56 \\
\hline PP & 0.80 & 0.78 & 0.61 \\
\hline \multicolumn{5}{c}{ Inter-day precision } \\
\hline LidHyd & 0.57 & 0.47 \\
\hline ChSal & 0.57 & 0.59 & 0.47 \\
\hline MP & 0.61 & 0.51 & 0.47 \\
\hline
\end{tabular}

\section{Stability}

The results of the stability study - change in the peak area of the analyte in $\%$ - are given in Table 5. According to the results of the stability study, it was shown that for the optimal terms of chromatography it is preferable to use a freshly prepared test and reference solutions within $24 \mathrm{~h}$.

Assay of a dosage form

The developed chromatographic method has been successfully applied for the analysis of test batches of the dental gel, containing $8.0 \%$ of ChSal, $1.5 \%$ of LidHyd, $0.15 \%$ of methylparaben and $0.05 \%$ of propylparaben. The results of determinations of the analysed components $(n=6)$ are summarised in Table 6.

Also the developed method was successfully used for in vitro release testing. Bioavailability evaluation was performed according to the results of the release dynamics study of ChSal and LidHyd from the gel samples using the method of dialysis through a semi-permeable membrane [34].

\section{CONCLUSIONS}

A new accurate analytical HPLC method has been worked out to be implemented in a regular analysis for a simultaneous assay of the active substances, choline salicylate and lidocaine hydrochloride, and preservatives - methylparaben and propylparaben - in a new dental gel. The developed HPLC method has been validated over the linearity, precision, accuracy and specificity. The proposed analytical method has been successfully applied for the analysis of test batches of the dental gel and has shown that it can be effective for the qualification of described substances in the pharmaceutical dosage forms. The developed method is distinguished by sufficient selectivity, linearity and high accuracy in the range of analysed concentrations with a correlation coefficient above 0.9990 .

Received 21 April 2021 Accepted 4 May 2021

Table 5. Stability studies for the analysed components in reference and test solutions

\begin{tabular}{|c|c|c|c|}
\hline \multirow{2}{*}{ Component } & \multirow{2}{*}{ Required limit } & \multicolumn{2}{|c|}{ RSD (\%) Equation } \\
\hline & & Reference solution & Test solution \\
\hline LidHyd & \multirow{4}{*}{$\leq 0.512$} & 0.164 & 0.343 \\
\hline ChSal & & 0.212 & 0.132 \\
\hline MP & & 0.229 & 0.281 \\
\hline PP & & 0.475 & 0.297 \\
\hline
\end{tabular}

Table 6. Results of the determination of active components and preservatives in the test series of a dental gel by developed HPLC method

\begin{tabular}{c|c|c|c|c}
\hline Gel series & ChSal & LidHyd & MP & PP \\
\hline 001 & $80.4525 \pm 0.0466$ & $14.8879 \pm 0.0295$ & $1.4928 \pm 0.0005$ & $0.4895 \pm 0.0013$ \\
\hline 002 & $80.2259 \pm 0.0372$ & $14.9983 \pm 0.0453$ & $1.4937 \pm 0.0006$ & $0.4901 \pm 0.0013$ \\
\hline 003 & $80.0717 \pm 0.2099$ & $14.8804 \pm 0.0303$ & $1.4888 \pm 0.0030$ & $0.4936 \pm 0.0022$ \\
\hline
\end{tabular}




\section{References}

1. Yu. Maslii, O. Ruban, Yu. Levachkova, S. Gureyeva, T. Kolisnyk, Pharmakeftiki, 32, 40 (2020).

2. CPMP/ICH/419/03: August 2003, Note for guidance on excipients, antioxidants and antimicrobial preservatives in the dossier for application for marketing authorisation of a medicinal product, Draft, Deadline for comments.

3. CPMP/QWP/115/95: July 1997, Note for guidance on inclusion of antioxidants and antimicrobial preservatives in medicinal products, CPMP and CVMP approval.

4. M. Dobrenić, I. Vidas, Acta Stomatol. Croat., 10, 51 (1976).

5. P. Firu, D. Stanciu, P. Zane, Schweiz. Rundsch. Med. Prax., 65, 111 (1976).

6. M. Grzymała-Siedlecka, Czas. Stomatal., 32, 109 (1979).

7. Ch. Hasenau, B. P. E. Clasen, D. Roettger, Z. Laryngol. Rhinol. Otol., 67, 576 (1988).

8. I. M. Rabinovich, G. V. Banchenko, O. F. Rabinovich, Stomatologiia, 78, 20 (1999).

9. G. Ramachander, F. D. Williams, J. F. Emele, J. Pharm. Sci., 62, 1498 (1973).

10. H. F. Salem, R. M. Kharshoum, O. M. Sayed, L. F. Abdel Hakim, J. Liposome Res., 29, 195 (2019).

11. K. Stawinski, E. Szponar, M. Zydorczak, Czas. Stomatol., 30, 373 (1977).

12. E. Weyna, Czas. Stomatol., 30, 871 (1977).

13. D. Donaldson, S. C. Gelskey, R. G. Landry, D. C. Matthews, H. S. Sandhu, J. Clin. Periodontol., 30, 171 (2003).

14. M. M. Doshi, M. D. Joshi, B. P. Mehta, U.S. Patent No 6,365,131, 2002.

15. S. Ghosh, G. Roy, B. Mukherjee, AAPS PharmSciTech, 10, 692 (2009).

16. A. P. Pandit, V. V. Pol, V. S. Kulkarni, J. Pharm., 2016, 1 (2016).

17. H. R. Shah, E. Reichel, B. G. Busbee, Local Reg. Anesth., 3, 57 (2010).

18. Y. Wei, M. P. Nedley, S. B. Bhaduri, X. Bredzinski, S. H. Boddu, AAPS PharmSciTech, 16, 455 (2015).

19. J. G. Grasselli, Anal. Chem., 53, 1111A (1981).

20. European Pharmacopoeia, 9th edn., European Directorate for the Quality of Medicines \& Health Care, Strasbourg (2017).

21. L. Kang, H. W. Jun, J. W. Mccall, J. Pharm. Biomed. Anal., 19, 737 (1999).

22. E. Ricci Júnior, M. V. L. B. Bentley, J. M. Marchetti, Rev. Bras. Cienc. Farm., 38, 107 (2002).

23. S. M. Waraszkiewicz, E. A. Milano, R. DiRubio, J. Pharm. Sci., 70, 1215 (1981).

24. Ö. Aksu, A. Bozdoğan, G. Kunt, Anal. Lett., 39, 751 (2006).
25. P. J. Palermo, J. B. Lundberg, J. Pharm. Sci., 67, 1627 (1978).

26. J. Dvorak, R. Hajkova, L. Matysova, et al., J. Pharm. Biomed. Anal., 36, 625 (2004).

27. A. Glushchenko, I. Bezruk, L. Ivanauskas, V. Georgiyants, ScienceRise Pharm. Sci., 2, 39 (2019).

28. R. Hajkova, P. Solich, J. Dvorak, J. Pharm. Biomed. Anal., 32, 921 (2003).

29. M. R. Lee, C. Y. Lin, Z. G. Li, T. F. Tsai, J. Chromatogr. A., 1120, 244 (2006).

30. P. E. Mahuzier, K. D. Altria, B. J. Clark, J. Chromatogr. A., 924, 465 (2001).

31. G. Popovic, M. Cakar, D. Agbaba, J. Pharm. Biomed. Anal., 33, 131 (2003).

32. D. Šatínský, J. Huclová, R. L. Ferreira, M. C. B. Montenegro, P. Solich, J. Pharm. Biomed. Anal., 40, 287 (2006).

33. E. Sottofatori, M. Anzaldi, A. Balbi, G. Tonello, J. Pharm. Biomed. Anal., 18, 213 (1998).

34. Yu. Maslii, O. Ruban, G. Kasparaviciene, et al., Molecules, 25, 5018 (2020).

35. Yu. S. Maslii, O. A. Ruban, O. P. Strilets, Ukr. Biopharm. J. 1, 58 (2017).

36. ICH Harmonized Tripartite Guideline Q2 (R1). Validation of Analytical Procedures: Text and Methodology Q2 (R1), in: Proceedings of the International Conference on Harmonization of Technical Requirements for Registration of Pharmaceuticals for Human Use, Geneva, Switzerland (2005).

37. State Pharmacopoeia of Ukraine: in 3 volumes, 2nd edn., Vol. 1, 1128, State Enterprise 'Ukrainian Scientific Pharmacopoeial Center for Quality of Medicines', Kharkiv (2015).

38. G. A. Shabir. Indian J. Pharm. Sci., 72, 421 (2010).

39. P. Perez-Lozano, E. Garcia-Montoya, A. Orriols, et al., J. Pharm. Biomed. Anal., 39, 920 (2005).

Yuliia Maslii, Ivan Bezruk, Anna Materiienko, Olena Ruban, Liudas Ivanauskas, Mariia Velia

\section{NAUJAS CHOLINO SALICILATO, LIDOKAINO HIDROCHLORIDO IR KONSERVANTU NUSTATYMO BŪDAS NAUJAME DANTU GELYJE NAUDOJANT AUKŠTO EFEKTYVUMO SKYSTINE CHROMATOGRAFIJA}

Santrauka

Sukurtas naujas aukšto efektyvumo skystinès chromatografijos analizès metodas, skirtas vienalaikiam cholino salicilatui, lidokaino hidrochloridui ir konservantams naujame dantu gelyje nustatyti. Metodas optimizuotas parenkant mobiliosios fazès sudètị ir detekcijos bangos ilgi. Naudojamas gradientinis atskyrimas acetonitrilu ir fosfatinio buferio tirpalu pH 3,0. Detekcija vykdoma esant $260 \mathrm{~nm}$ bandos ilgiui. 